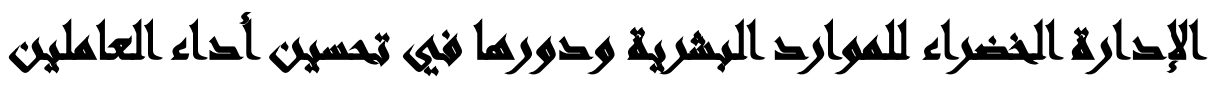 بالإيارايت المعليهية
}

\section{[1 \{]}

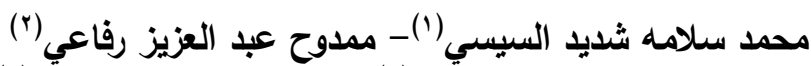

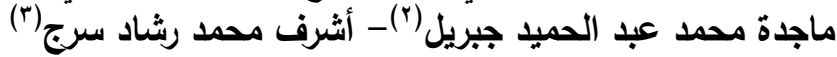

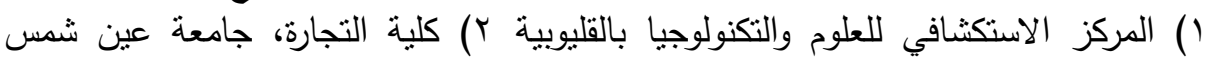

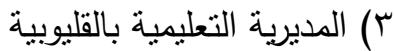

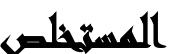

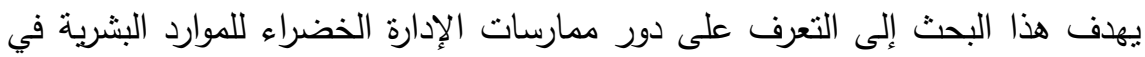
تحسين أداء العاملين بالإدارات التعليمية بمحافظة القليوبية، وذللك من أجل العمل على التحلى تحسين

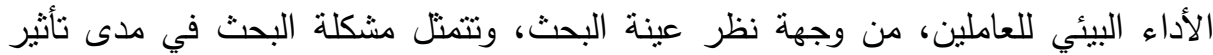

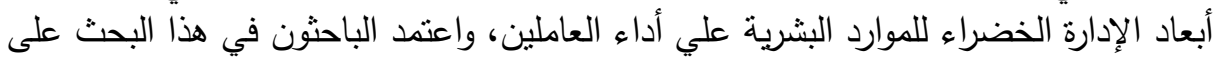

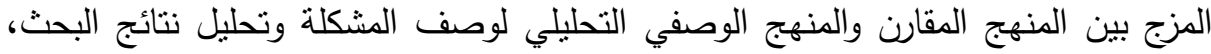

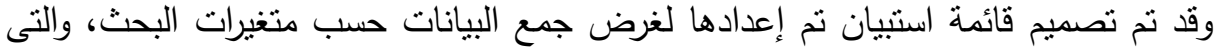

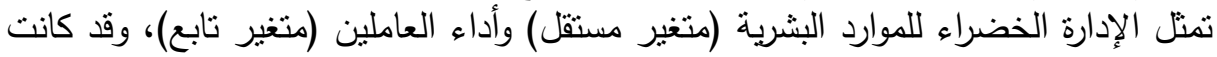

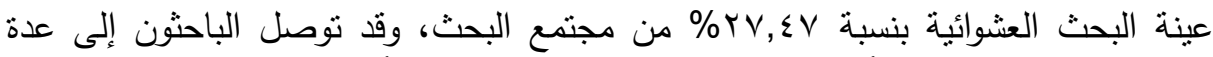

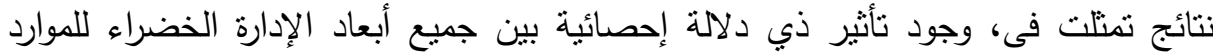

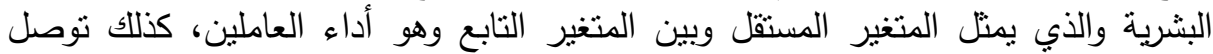

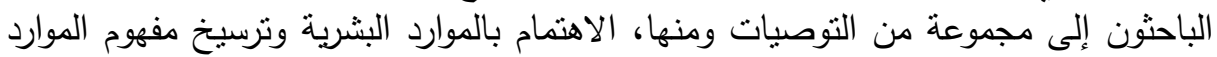

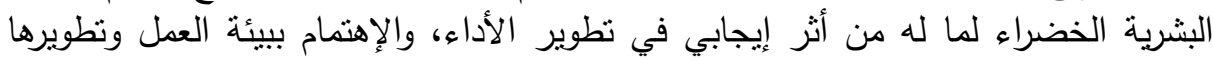

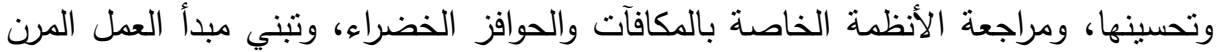

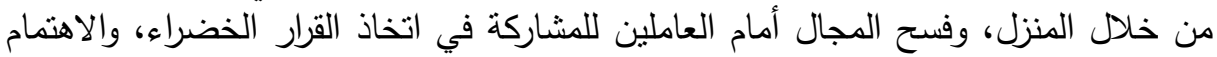

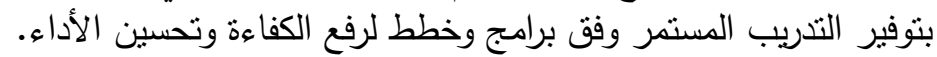

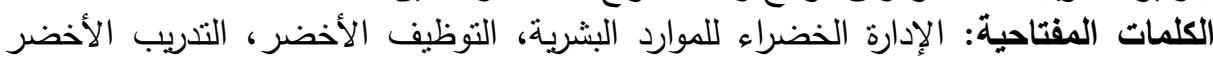

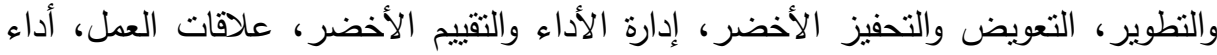




\section{axis}

إن مشكلة التلوث البيئي ليست مشكلة جديدة أو طارئة، وإنما الجديد فيها هو زيادة شدة

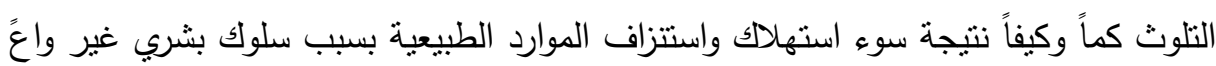
أو مدرك لما يحدث حوله من مشكلات بيئية خطيرة تؤثر سلباً على المحيط الحيوي من حوله تلوث الأرض والمياه والهواء وتسنتزف الطاقة وتسبب خلل في النتوع الحيوي والنظم الايكولوجية والتغيرات المناخية نتيجة لهذا التدهور البيئي، لذلك يتحول العالم اليوم إلى ولى ولى

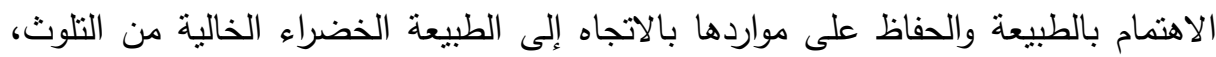

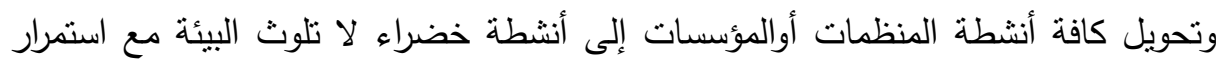
تطويرها حتى تصل المؤسسة أو المنظمة إلى أن تكون منظمة خضراء، وحيث أن الموارد النهاء البشرية الخضراء تلعب دوراً هاما في إنقاذ الأرض من خلال إتباع الممارسات صديقة البيئة

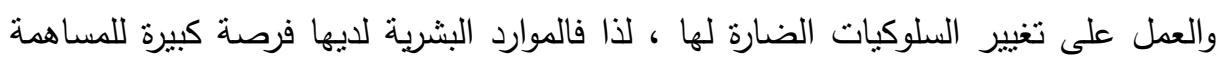
في الحركة الخضراء (Shaikh,2010)، وهذا هو الدور الذي تلعبه إدارة الموارد البشرية في في لهين كل منظمة ومؤسسة.

ونظراً لأن أثنار التلوث تمند إلى خارج الحدود ولا تقتصر على مكان بعينه وحيث أن

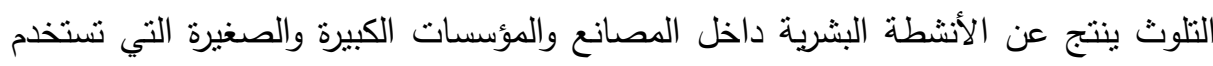

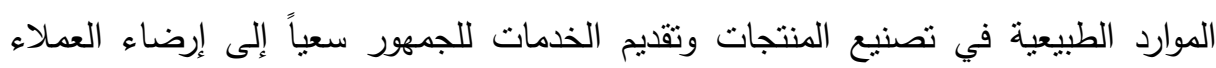

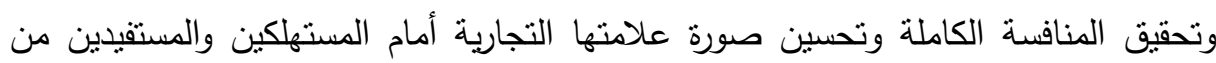

فكانت النداءات الدولية بداً من مؤنمر الأمم المتحدة عن بيئة الإنسان الذي عقد عام

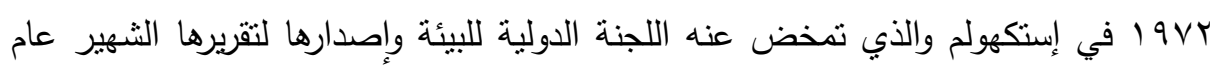

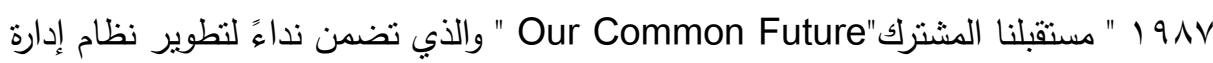
بيئي فعال، لذلك نوجه نظر المهتمين بنظم الإدارة إلى الإدارة الخضراء وخاصة إدارة الموارد

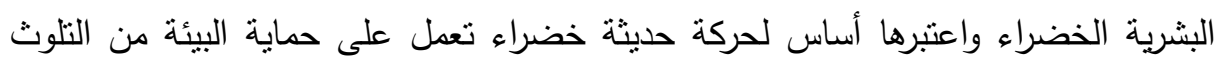
بالحفاظ على الأرض والمياه والهواء والطاقة من مستقبل مظلم إذا استمر الإنسان في أنشطته بلا اهتمام بالبيئة من حوله، لذلك فإن السلوكيات والأنشطة والممارسات التي يقوم بها العنصر

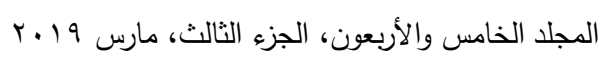


البشري داخل المؤسسات يمكن تحويلها إلى ممارسات خضراء وأنشطة خضراء وسلوك أخضر

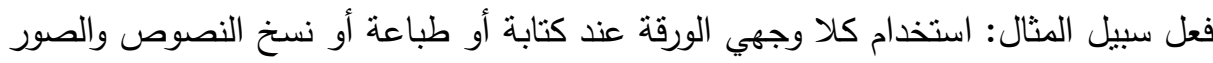
( فهذا سوف يقلل استهلاك الكهرباء والحفاظ على الأثجار)، كذلك إغلاق جهاز الكمبيوتر

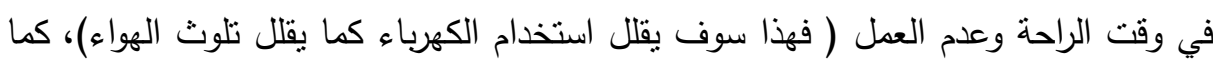

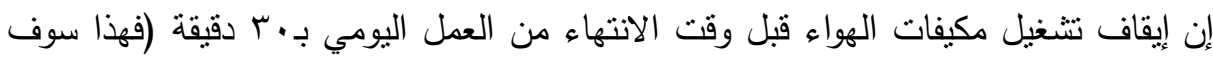
يقلل من استهلاك الكهرباء) كذلك ينخفض انبعاث الكربون عند تقليل أعمال الطباعة الورقية.

\section{and ILAn}

تتمركز مشكلة البحث حول دور ممارسات الإدارة الخضراء للموارد البشرية في تحسين أداء العاملين، حيث أن الأثار البيئية الناجمة عن استهلاك الموارد واسنتزافها بسبب الإداب الممارسات البشرية الخاطئة من العاملين داخل المؤسسات والتي ينتج عنها إهدار الموارد الطبيعية والاقتصادية وزيادة التلوث البيئي الذي لا يقتصر على مكان محدد بل ينتشر ويؤثر

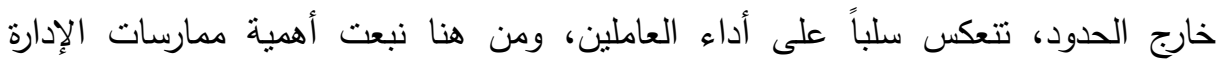
الخضراء للموارد البشرية وقد إفاد بذلك بعض الدراسات السابقة ومنها: - دراسة Hiba Awad Masri (2016) بعنوان:Assessing Green Human Resources Management Practices in West Bank: An Exploratory Study

" تقييم ممارسات الإدارة الخضراء للموارد البشرية في الضفة الغربية :دراسة استكشافية"

تهدف الدراسة إلى تقييم أفضل ممارسات الإدارة الخضراء للموارد البشرية (GHRM) في تصنيع الثركات من القطاعات الصناعية الثلاث (الغذائية والكيميائية والصناعات الدوائية) في الضفة الغربية،وسيتم ذلك من خلال تحقيق هدفين أولهما: سوف نستكثف مدى شركات التصنيع الفلسطينية تستخدم الممارسات GHRM لزيادة التزام الموظفين والوعي بالبيئة، وثانيهما: سوف يحدد المتغيرات الرئيسية/ العوامل التي تعزز تتفيذ GHRM وما هي العقبات التي تواجه هذه الحركة في تصنيع المنظمات الفلسطينية والفوائد المتوقعة من ممارسات

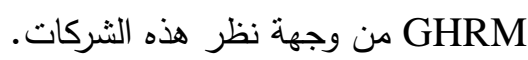


وقد استخدم نهج الأسلوب المختلطة من خلال جمع كل من البيانات الكمية والنوعية، كما اعتمدت في جمع البيانات المقابلة والاستبانة كأداة لجمع البيانات. وعند استخلاص النتائج، أن المنظمات تستخدم ممارسات GHRM على مستوى معتدل

$$
\text { لنتجيع المناصرة للبيئة في سلوك موظفيها. }
$$

- دراسة (2016) (Amara, N. B., \& Atia, L.

\section{E-Training and Its Role in Human Resources Development}

$$
\text { " دور التدريب الإكتروني في تنمية الموارد البشرية" }
$$

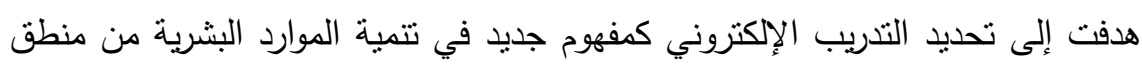

$$
\text { التقدم العلمي، وأهمية تكنولوجيا المعلومات في مجال التدريب. }
$$

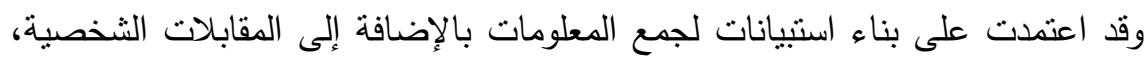

$$
\text { كما استخدمت المنهج الوصفي التحليلي في تفسير النتائج. }
$$

وقد استتنجت أن التدريب الإكتروني هو واحدة من القضايا المهمة في تأهيل وتدريب

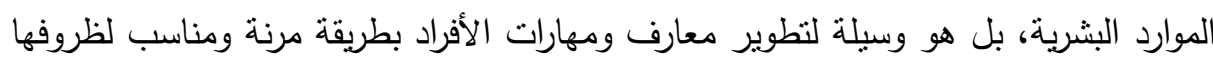

$$
\text { دون الحاجة إلى أعباء إضافية. }
$$

وإن التدريب من خلال شبكة الإنترنت ونوفر أجهزة الاتصالات الحديثة فرصة ممتازة

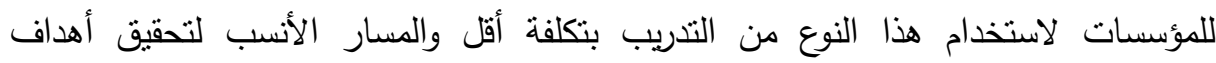

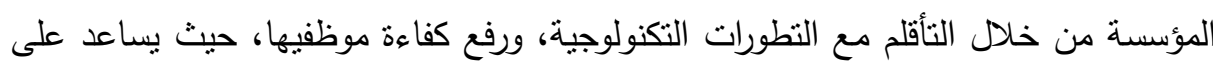
تقليل التكلفة المادية وتوفير الوقت والجهر للحصول على تدريب خاص.

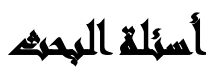

$$
\text { يتمثل التساؤل الرئيس للبحث في: }
$$

ماهي الإدارة الخضراء للموارد البشرية وما دورها في تحسين أداء العاملين بالإدارات

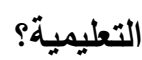

وينبثق من التساؤل الرئيس التساؤلات الفرعية التالية:

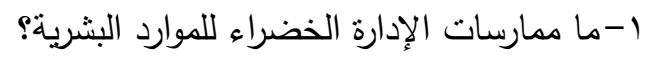


r-ما أهمية الإدارة الخضراء للموارد البشرية بالإدارات التعليمية؟

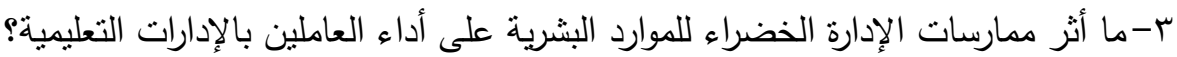

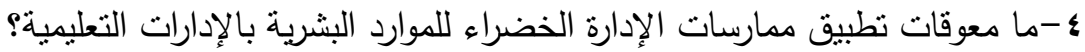

\section{أمسا اهن المهمث}

$$
\text { يهذف هذا البحث إلى ما يلي: }
$$

• التعرف على ممارسات الإدارة الخضراء للموارد البشرية بالإدارات التعليمية. • التعرف في الوضع الراهن على واقع الإدارة الخضراء للموارد البشرية بالإدارات التعليمية.

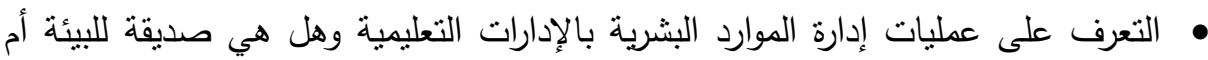

الوقوف على نقاط القوة والضعف في عمليات إدارة الموارد البشرية بكل إدارة وسبل التغلب على نقاط الضعف وتعزيز نقاط القوة. تحسين أداء العاملين بالإدارات التعليمية من خلال الكثف عن نقاط القوة والضعف في أداء الأنشطة صديقة البيئة. • تسليط الضوء على مدى أهمية ممارسات الإدارة الخضراء للموارد البشرية في الإدارات الإه التعليمية.

التعرف على دور ممارسات الإدارة الخضراء للموارد البشرية في تحسين أداء العاملين

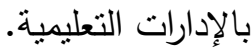
• التعرف على المعوقات التي تحول دون تطبيق ممارسات الإدارة الخضراء للموارد البشرية

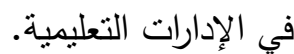
• زيادة الوعي لدى المسئولين والعاملين بأهمية الإدارة الخضراء للموارد البشرية. 


\section{فروض المهنه}

الفرض الرئيس: لا يوجد تأثير ذو دلالة إحصائية لممارسات الإدارة الخضراء للموارد

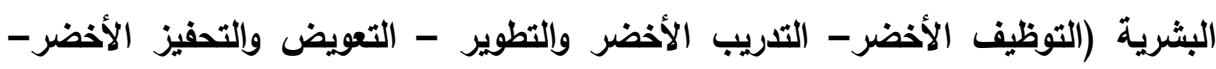
إدارة الأداء والتقييم الأخضر - علاقات العمل) على أداء العاملين بالإدارات التطليمية. وينبثق عنه الفروض الفرعية النالية: الفاء ا. لا يوجد ثأثثر ذو دلالة إحصائية للتوظيف الأخضر للموارد البشرية على أداء العاملين بالإدارات النعليمية. r. لا يوجد نأثير ذو دلالة إحصائية للتنريب الأخضر وتطوير الموارد البشرية على أداء العاملين بالإدارات التعليمية. r. لا يوجد تأثثر ذو دلالة إحصائية للتعويض والتحفيز الأخضر للموارد البشرية على أداء العاملين بالإدارات التعليمية. ع. لا يوجد تأثير ذو دلالة إحصائية لإدارة الأداء والثقويم الأخضر على أداء العاملين

$$
\text { بالإدارات التعليمية. }
$$

ه. لا يوجد تأثبر ذو دلالة إحصائية لعلاقات العمل الخاصة بالموارد البشرية على أداء

$$
\text { العاملين بالإدارات التعليمية. }
$$

\section{مسور= المجمن}

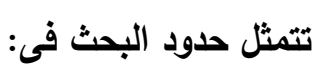

1-الحدود البشرية: استهدف البحث العاملين بالمجموعة النوعية للوظائف المكتبية

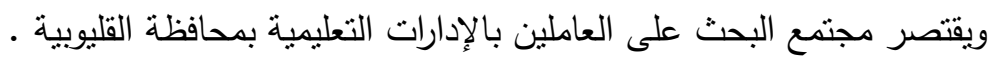
ץ-الحدود المكانية: اقتصر البحث على الإدارات التعليمية بمحافظة القليوبية.

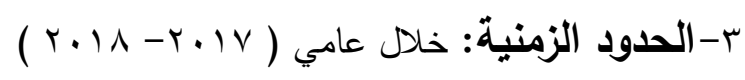

ع-الحدود العلمية: اقتصر البحث علي ممارسات الإدارة الخضراء للموارد البثرية وأبعادها كمتغير مستقل، وأداء العاملين كمتغير تابع. 


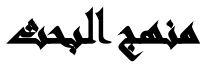

تحقيقاً لأهداف البحث واختبار فروض البحث قام الباحثون باستخدام منهجي البحث التاليين: • المنهج الوصفي التحليلي: في وصف المشكلة وتحليل البيانات التي جمعها الباحثين بواسطة أداة البحث، وكذللك في تحلل الأدبيات والبحوث والدراسات السابقة. • المنهج المقارن: في المقارنة بين عمليات الإدارة الخضراء للموارد البشرية بالإدارات التعليمية المختلفة، والتعرف على مدى تأثثرها في تحسين أداء العاملين بالإدارات

\section{أهمية المهيه}

تتبع أهمية هذا البحث من خلال الأهمية التي تحتلها الإدارة الخضراء للموارد البشرية، سواء في كونها دعامة أساسية للنشاط الاقتصادي في الحفاظ على الموارد الطبيعية وترشيد

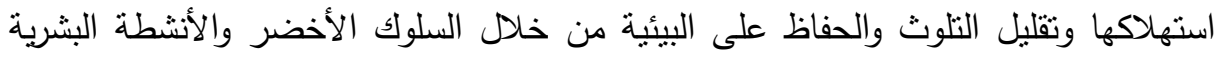
الخضراء، وفي كونها تلبي احتياجات التتمية المستدامة والحفاظ على حقوق الأجيال القادمة. كما يوضح البحث مدى مساهمة الإدارة الخضراء للموارد البشرية في تحسين اداء العاملين بالإدارات التعليمية، بالإضافة إلى تحديد نقاط القوة والضعف في ممارسات الإدارة

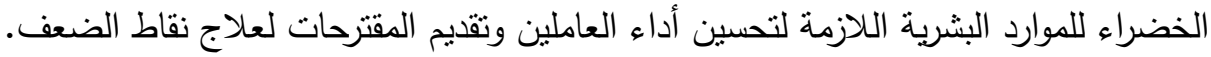

\section{الصواسايت المابري}

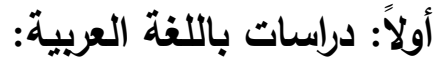

• دراسة (الزبيدي، 1 + †): هدفت إلى تحديد دور ممارسات إدارة الموارد البشرية الخضراء في تحقيق متطلبات المواطنة البيئية، وقد تم النطبيق ميدانياً على الثركة العامة للزيوت النباتية، تكونت عينة الدراسة من (30) فرداً نم اختيارهم بشكل عشوائي، وقد تم استخدام المنهج الوصفي التحليلي، وقد تم استخدام الاستبانة كأداة لجمع البيانات والمعلومات، وقد

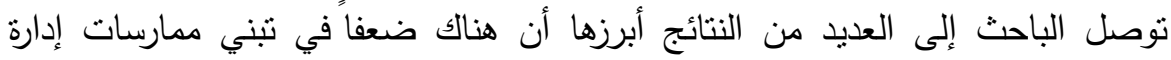
الموارد البشرية الخضراء من قبل إدارة الشركة العامة للزيوت النباتية، كما أن هناك الك

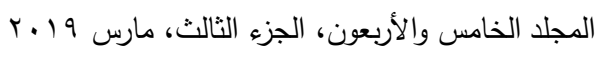


ضعفاً في شيوع ثقافة المواطنة البيئية بين العاملين في الثركة العامة للزيوت النباتية .كما

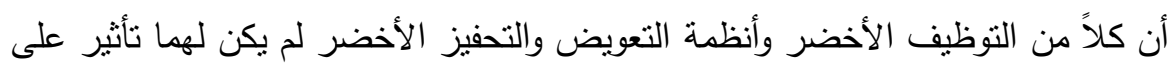
المواطنة البيئية .

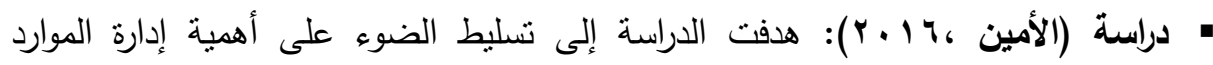

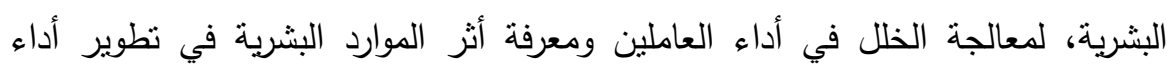

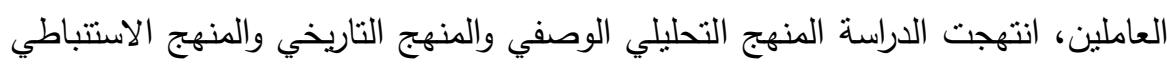

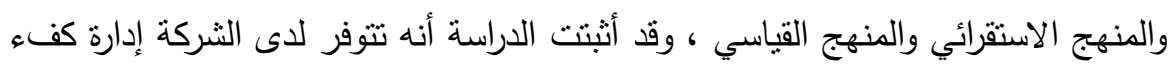
للموارد البشرية تعطل وفق رؤية إستراتيجية وتطبق الأساليب الحديثة في إدارة الموارد البشرية.

دراسة (الضالعي ، 1 ب †): يهدف البحث إلى تحليل دور الإدارة الإستراتيجية للموارد البشرية في تحسين أداء العاملين بالجامعات الحكومية البينية صنعاء،اعتمد على استخدام المنهج الوصفي التحليلي، ومن توصل البحث إلى ضعف دئ درجة ممارسة الإدارة الإستراتيجية للموارد البشرية في جامعتي صنعاء وتعز وكذلك ضعف مستوي أداء العاملين في الجامعنين.

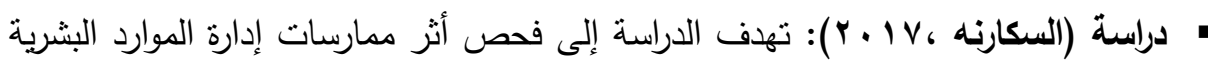

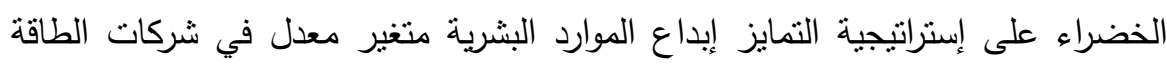

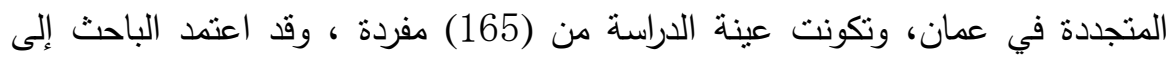

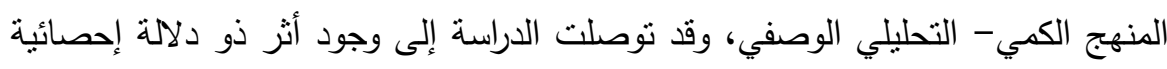

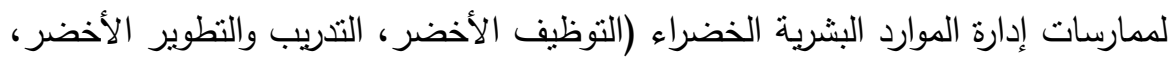

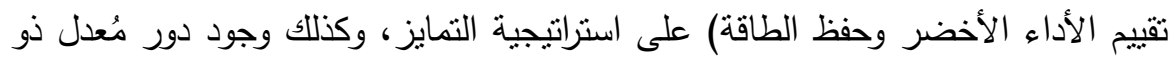
دلالة إحصائية للإبداع على العلاقة بين ممارسات إدارة الموارد البشرية الخضراء

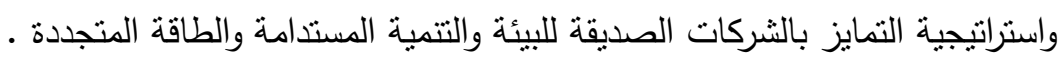
ثانياً: دراسات باللغة الإنجليزية: • دراسة (Opatha, 2014): هدف البحث إلى تنسيط الأفكار العامة النظرية فيما يتعلق

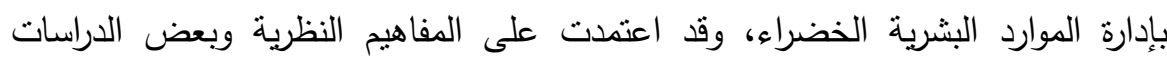


البحثية السابقة، وقد استتنجت أن هناتك العديد من الثغرات التي يجب ملؤها وهي الاهتمام بإدارة الموارد البشرية الخضراء، والدراسات النظرية والتطبيقية اللازمة لتعزيز مجموعة لهابة

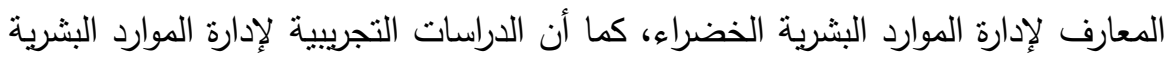

$$
\text { الخضراء في سريلانكا ليست منوفرة. }
$$

• دراسة(Ruchismita, 2015): هدفت الدراسة إلى تشجيع الممارسات الصديقة للبيئة

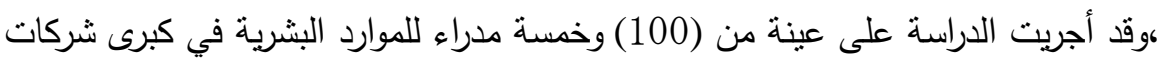
تكنولوجيا المعلومات في الهند، وتم اللجوء إلى المنهج الوصفي التحليلي من خلال استبانة تم إعدادها خصيصاً لتحقيق أهداف الدراسة، توصلت الدراسة إلى أن نظم الإدارة البيئية والممارسات الصديقة للبيئة (الموارد البشرية الخضراء) ساهمت في زيادة حصة الأرباح للشركة . • دراسة (Rimi, 2016):هدفت الدراسة إلى وضع نموذج لتحسن ممارسات إدارة الموارد

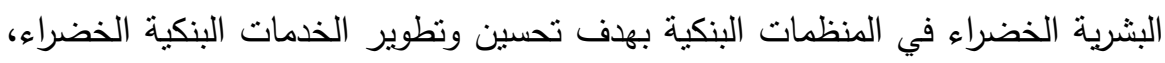

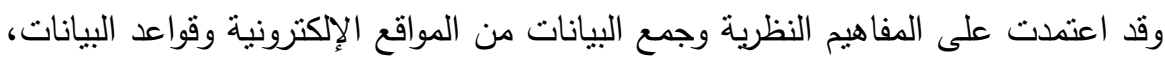
وقد أوضحت أن الصناعة المصرفية تحتاج إلى التركيز على الموارد البشرية واستخدام

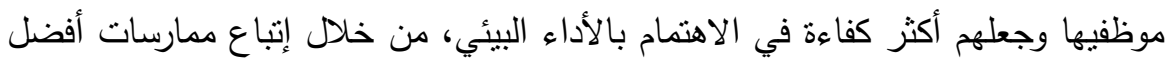

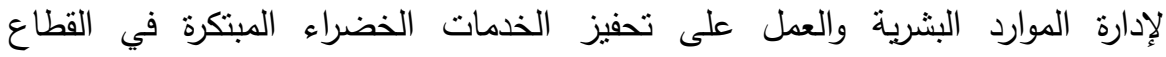
المصرفي، وقد نتج عن ذلك أن التخضير البنكي للخدمات أنه واحد من أهم العوامل المختلفة التي تساعد على تحسن صورة وسمعة المؤسسة البنكية كما اعتبرت الإدارة الخضراء للموارد البشرية هي تجديد للخدمات البنكية الخضراء. • دراسة (Sharma,2016):هدفت الدراسة إلى التعرف على مدى مبادرات إدارة الموارد البشرية الخضراء، ويتتاول بالتفصيل أنموذج عمليات الموارد البشرية العاملة في إدارة البها الموارد البشرية الخضراء وتقدم هذه الدراسة خلفية نظرية عن إدارة الموارد البشرية الخضراء

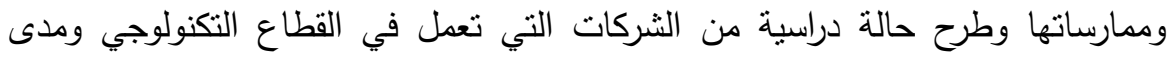
مساهمة الموظفين في إدارة الموارد البشرية الخضراء كما وتقوم الدراسة بتسليط الضوه

$$
\text { المجلد الخامس والأربعون، الجزء الثالث، مارس } 19
$$


على دور النساء في جميع أنحاء العالم لتعزيز ومراعاة الفوارق بين الجنسين وفي مكان العمل كما إنها تقوم بالتدريب ونصح الثشابات الطموحات من النساء في الإسهام بخبراتهن في أولويات العمل والحياة .

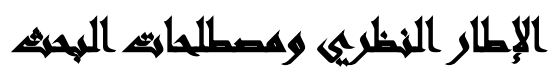

\section{أولاً: مفهوم الإدارة الخضراء للموارد البشرية:}

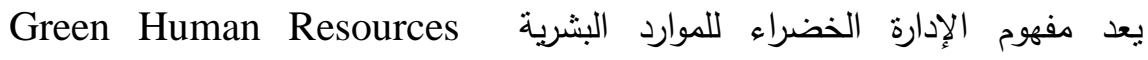
Management الفكر الإداري الذي يربط بين أنشطة إدارة الموارد البشرية وبين الإدارة البيئية.

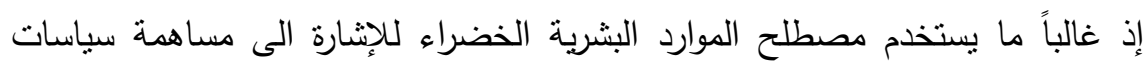

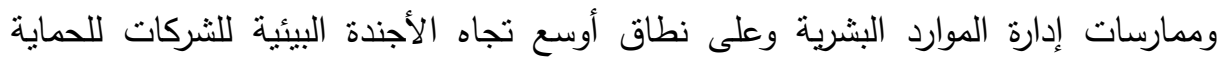

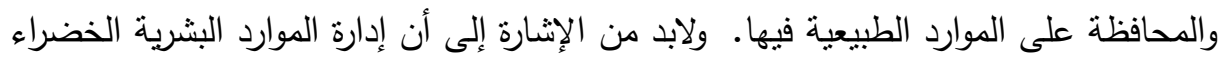

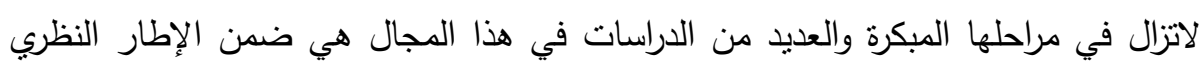
- (Jabbour, 2013) كما تشير إدارة الموارد البشرية الخضراء الى دمج الإدارة البيئية للمنظمة مع أهداف ممارسات إدارة الموارد البشرية كالتوظيف والاختيار والتدريب والتطوير وإدارة الأداء والتقييم والمكافآت (Muller, 2010) ) كما عرفت بأنها: ممارسات الموارد البشرية الصديقة للبيئة بما يؤدي إلى كفاءة أفضل

وتكلفة أقل ومستويات أعلى من ارتباط العاملين مع منظماتهم) (Marhatta, 2013) . ثانياً: مفهوم أداء العاملين: إن الأداء مفهوم واسع يعبر عن أسلوب المنظمة في استثمار مواردها المتاحة وفق معايير واعتبارات متعلقة بأهدافها فيظل مجموعة من المتغيرات الداخلية والخارجية التي تتفاعل معها الوحدة الاقتصادية في سعيها لتحقيق كفاءتها وفاعليتها لتأمين

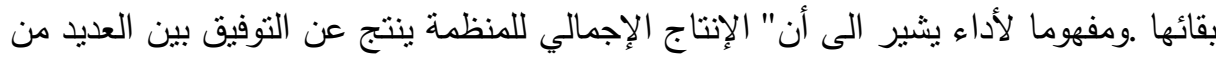

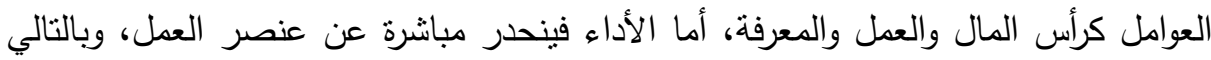
فإن كل عامل سيعطي الأداء الذي ينتاسب مع قدراته وطبيعة عمله(نعمة ، . . . T).

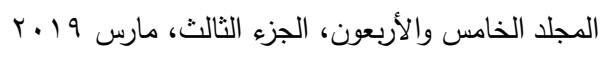


إن الأداء يتضمن الأسلوب والكيفية والزمن المستغرق في إنجاز الأعمال، كذلك يتضمن

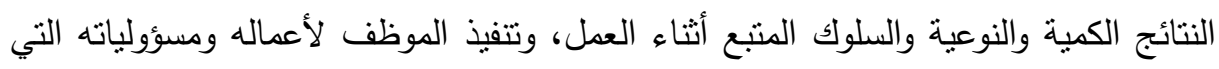

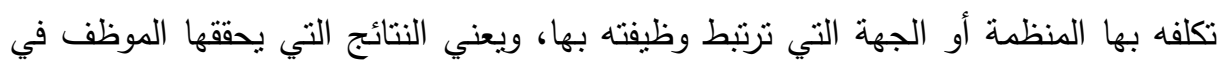
المنظمة وبشكل يحقق التفاعل بين السلوك والإنجاز ، أو أنه مجموع السلوك والنتائج التي

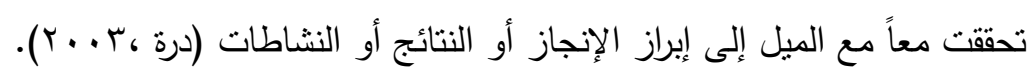
إن أداء العاملين يعثبر المحور الرئيس الذي تدور حوله جهود المنظمات كونه يشكل أهم الهم

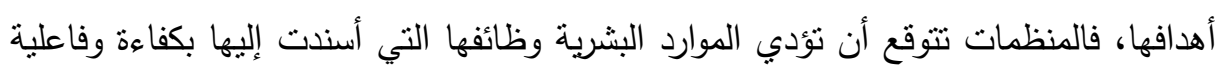

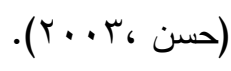

\section{إلجراعايت الهمهث}

أداة البحث: اعتمد هذا البحث على وسيلة الاستبانة (Questionnaire) كأداة رئيسة

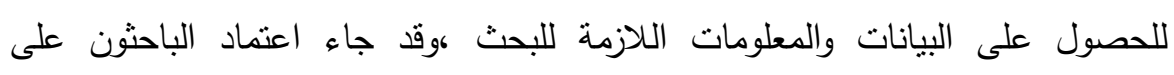

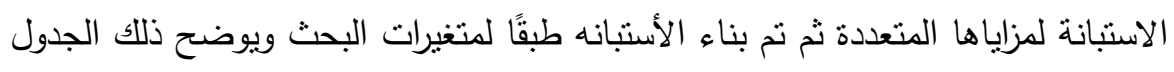

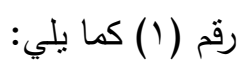
جدول رقم (1) (1)

\begin{tabular}{|c|c|c|}
\hline عدد العبارات & البيان & المحاور \\
\hline 270 & الإدارة الخضراء للموارد البشرية & المتغير المستقل \\
\hline 8 & التوظيف الاخضر & $\gamma_{g}$ \\
\hline 15 & التندريب الاخضر والنظوير & ثانيا \\
\hline 14 & التعويض والتحفيز الاخضر & ثنالثًا \\
\hline 11 & إدارة الاداء والثقويم الاخضر & رابعا \\
\hline 22 & علاقات العمل مات & خَامسا \\
\hline 16 & أداء العاملين & المتغير التابع \\
\hline
\end{tabular}

- مجتمع البحث: قد تم اختيار أربعة إدارات تعليمية بمحافظة القليوبية بنسبة سبرسبر

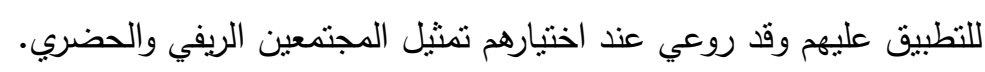

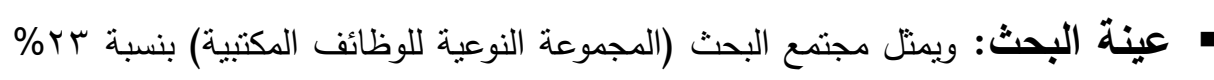

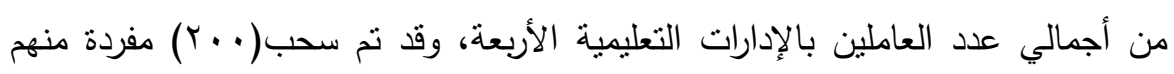


كعينة عثوائية بلغت نسبتها YrV, \&V من مجتمع البحث ، وقد إجري البحث خلال

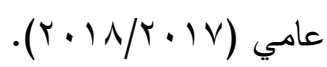

- أساليب التحليل الإحصائي المستخدم في البحث: ولتحقيق أهداف البحث واختبار فروض البحث، قد تم استخدام الأدوات الإحصائية التالية: () إجراء اختبار الثبات والصدق الذاتي (Reliability Test): لأسئلة الاستبانة المكونة من الأنة

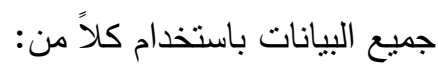
ل معامل ألفا كرونباخ (Cronbachs Alpha): وتم استخدامه لقياس الاتساق الداخلي لعبارات البحث للتحقق من صدق الأداة، وكذلك لبحث مدى الاعتماد على نتائج البحث

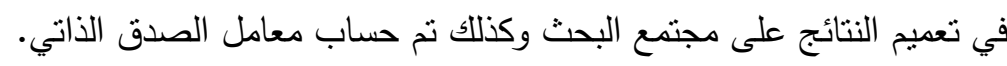
ل معاملات الارتباط لبيرسون: لتحديد مدى قوة العلاقة بين محاور الإدارة الخضراء للموارد البشرية وأداء العاملين كما في الفرض الرئيس للبئ للبحث.

r أساليب الإحصاء الوصفي: لتوضيح منوسط وتباين الآراء حول عناصر الأسنبانة: r) تحليل التباين الأحادي (One- Way Anova): للتحقق من دلالة الفروق بين الإدارات التعليمية تعزي إلى متغيرات البحث ويتم ذللك بالمقارنة بين المتوسطات. §) أسلوب (الانحدار المتعدد القياسي): تم استخدام هذا الاختبار لاختبار الدلالة الإحصائية

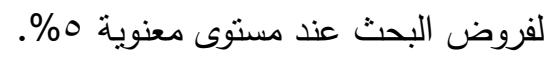

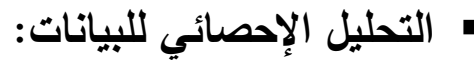
ل ثبات وصدق الاستبانة.يوضح الجداول رقم (Y) نتائج تحليل الثبات والصدق الذاتي

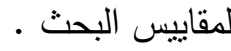
جدول رقم (r): معاملى الثنات لألفا كرونباخ والصدق الذاتى للاستبانة

\begin{tabular}{|c|c|c|c|c|}
\hline معامل الصدق & $\begin{array}{c}\text { معامل الثبات } \\
\text { (Alpha) }\end{array}$ & العبارات & البيـان & المحاور \\
\hline 0.988 & 0.977 & 70 & الإدارة الخضراء للموارد البشرية & المتغير المستقل \\
\hline 0.941 & 0.885 & 8 & التوظيف الأخضر & أولاً \\
\hline 0.970 & 0.941 & 15 & التدريب الأخضر والتطوير & ثُانياً \\
\hline 0.966 & 0.934 & 14 & التعويض والتحفيز الأخضر & ثالثاً \\
\hline 0.946 & 0.895 & 11 & إدارة الأداء والتقويم الأخضر & رابعاً \\
\hline 0.970 & 0.941 & 22 & علاقات العمل & خامساً \\
\hline 0.965 & 0.932 & 16 & أداء العاملين & المتغير التابع \\
\hline
\end{tabular}


الجدول رقم(ץ) يعبرعن نتائج اختبار الثابت والصدق الذاتي لمتغيرات البحث، وحيث أن قيم ألفا كرونباخ لجميع محاور متغير الإدارة الخضراء للموارد البشرية وكذلك متغير أداء العالمين أكبر من (•7\%) وتعني هذه القيم نوافر درجة عالية جداً من الثبات الداخلي لجميع لإدرة

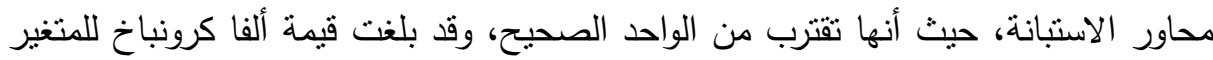

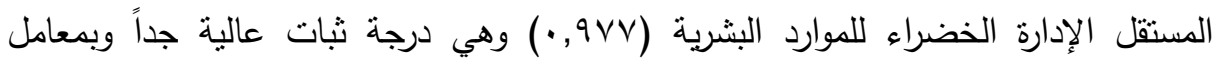

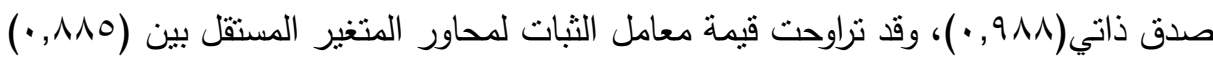
للتوظيف الأخضر و (اء9,، •) للتدريب الأخضر وعلاقات العمل وهو ثبات مرتفع جداً ،

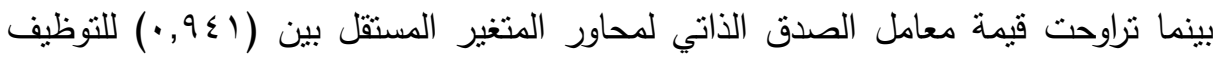

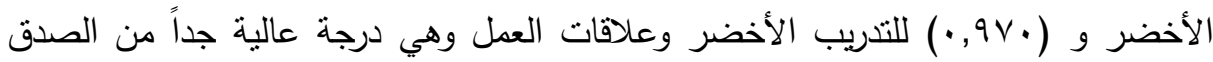

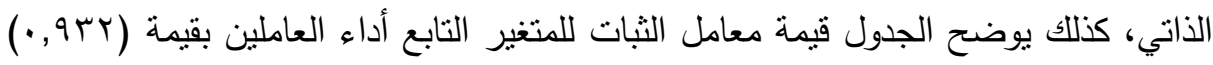
وهي درجة عالية جداً من الثبات الداخلي وبمعامل صدق ذاتي بقيمة (970, • •) وهي درجة لونة

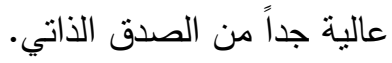
ومن ثم يمكن القول بأن المقاييس التي اعتمد عليها البحث لقياس تأثنير ممارسات الإدارة

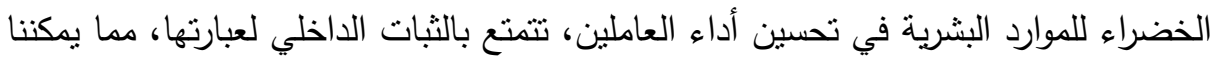
من الاعتماد على هذه الإجابات في تحقيق أهداف البحث وتحليل نتائجه.

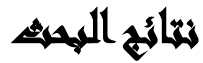

$$
\text { - اختبار الفرض الرئيس للبحث: }
$$

إن الفرض الرئيس للبحث هو:" لا يوجد تأثير ذو دلالة إحصائية لممارسات الإدارة الخضراء للموارد البشرية (التوظيف الأخضر -التدريب الأخضر والتطوير - التعويض والتحفيز الاخضر - إدارة الأداء والتقييم الأخضر - علاقات العمل) على أداء العاملين بالإدارات 
لاختبار هذا الفرض تم استخدام معامل ارتباط بيرسون ويعرض ذللك الجدول رقم (r)

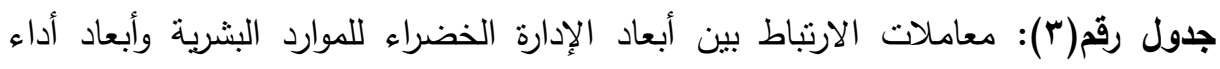
العاملين

\begin{tabular}{|c|c|c|c|c|c|}
\hline \multicolumn{5}{|c|}{ المتغير المستقل (الإدارة الخضراء للموارد البشرية) } & متغيرات البحث \\
\hline علاقات & والتقييم الأخضر الأداء & الألتحفيز & التنريب الأخضرير & الأخضر & \multirow[t]{2}{*}{ (أداء العناملين) التابع) } \\
\hline$\cdot, \wedge 0 . *$ & $\cdot, \wedge 9$. & $\cdot, \Lambda Y r^{* *}$ & $\cdot, V R T^{* *}$ & $\cdot, \varepsilon Y 0^{* *}$ & \\
\hline
\end{tabular}

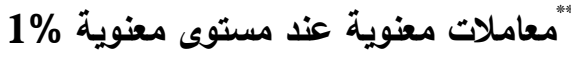

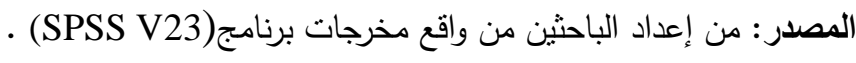

$$
\text { ويتضح من الجدول (r) ما يلي: من إعناد }
$$

• وجود ارتباط طردي قوى بين المتغير (إدارة الأداء والثقييم الأخضر) كأحد أبعاد (المتغير

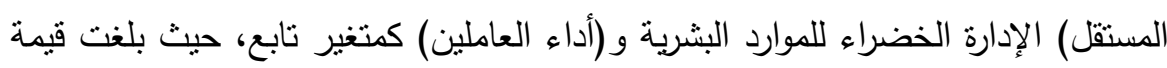

$$
\text { معامل الارتباط (0.890) ومعنوي عند مستوى معنوية 1\% الادرة }
$$

• كما يوجود ارتباط طردي قوى بين المتغير (علاقات العمل) كأحد أبعاد (المتغير المستقل)

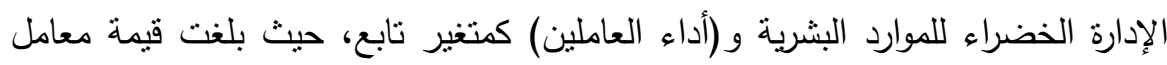

$$
\text { الارتباط (0.850) ومعنوي عند مستوى معنوية 1\%. }
$$

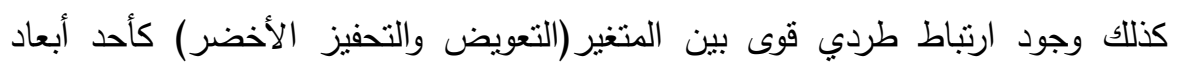

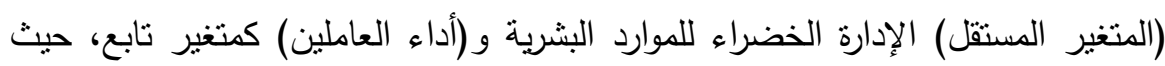
بلغت قيمة معامل الارتباط (0.822) ومعنوي عند مستوى معنوية 1\%. • وجود ارتباط طردي قوى بين المتغير(التدريب الأخضر والتطوير) كأحد أبعاد (المتغير

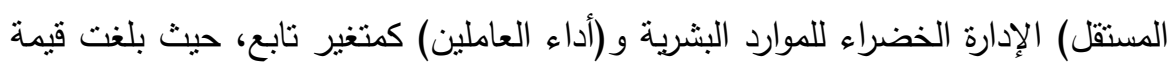
معامل الارتباط (0.733) ومعنوي عند مستوى معنوية 1\% الادرة

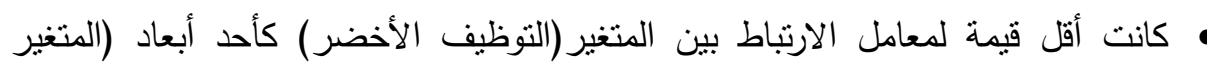

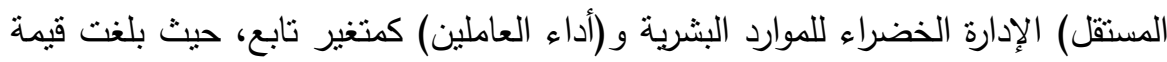


معامل الارتباط (0.452) مما يدل على وجود علاقة طردية منوسطة بين المتغيرين

$$
\text { ومعنوية عند مسنوى معنوية 1\%. }
$$

مما سبق يتضح وجود علاقة جوهرية بين ممارسات الإدارة الخضراء للموارد البشرية

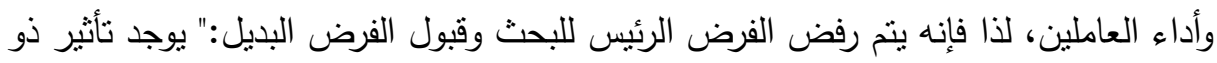

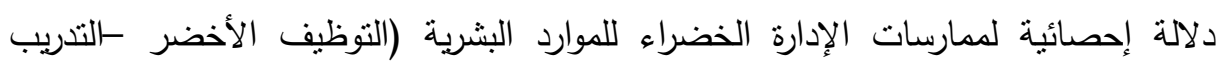
الأخضر والتطوير - التعويض والتحفيز الاخضر - إدارة الأداء والثقييم الأخضر - علاقات الأدات العمل) على أداء العاملين بالإدارات التعليمية " محل البحث. • تعليل الانحدار المتعدد القياسي: يستخدم للتنبؤ بقيمة المتغير التابع من خلال بلإل المتغيرات المستقلة، وذللك من خلال تمثيل العلاقة بين المتغير التابع والمتغيرات المستقلة، لذا نم استخدام تحليل الانحدار المتعدد القياسي لتحديد أثز ممارسات الإدارة الخضراء للموارد البشرية على أداء العاملين. جدول رقم (ء): تحليل الانحدار المتعدد للعلاقة بين أبعاد الإدارة الخضراء للموارد البشرية

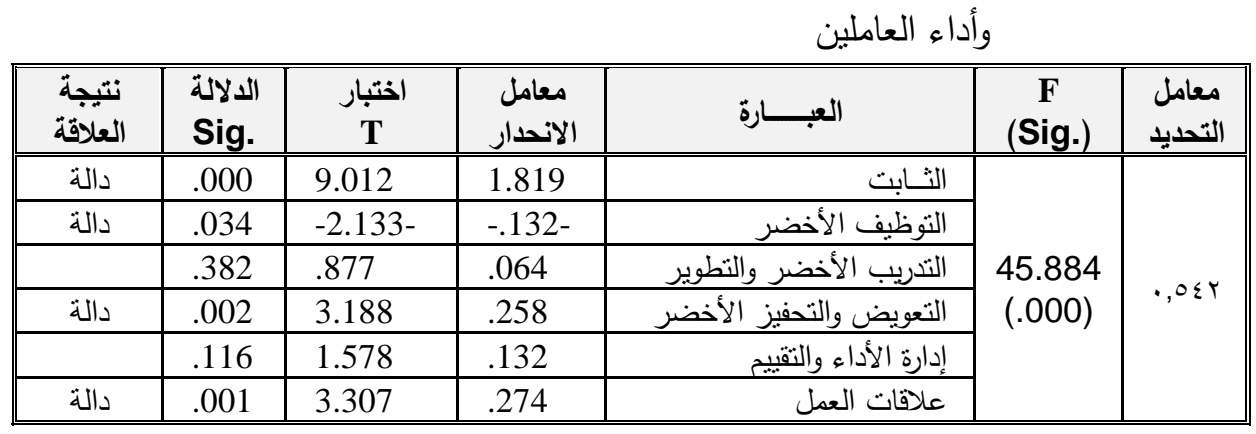
المصدر: من إعداد الباحثين من واقع مخرجات برنامج (SPSS V23) .

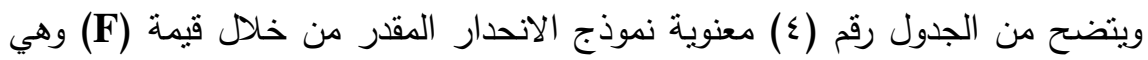

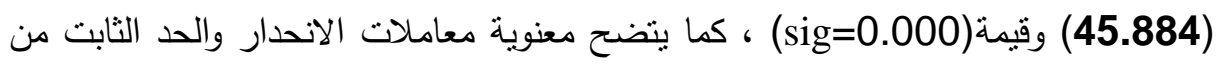

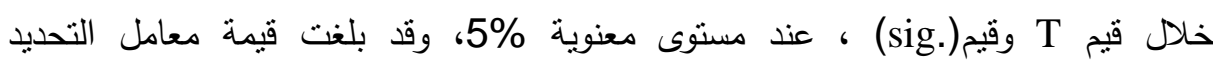

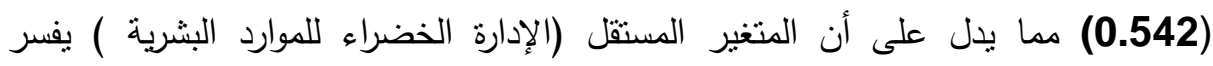
ץ, §॰\% من التغيرات التي تحدث في المتغير التابع (أداء العاملين).

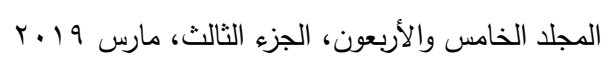


كما يوضح الجدول رقم (ع) أنه نوجد علاقة دالة إحصائياً بين أبعاد المتغير المستقل (الإدارة الخضراء للموارد البشرية ) والمتغير التابع (أداء العاملين) .

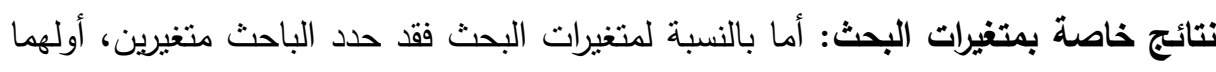
الإدارة الخضراء للموارد البشرية كمتغير مستقل ويشمل خمسة مؤشرات، (التوظيف الأخضر -

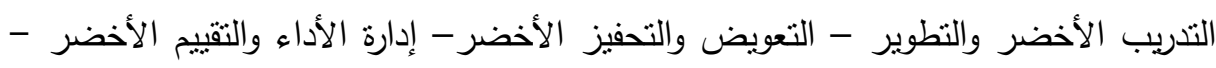

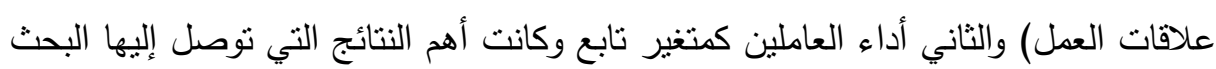

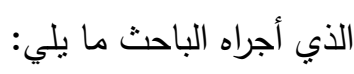
- بالنسبة للإدارة الخضراء للموارد البشرية: أنثبت البحث أن الإجمالي العام لمتوسط أراء العينة من العاملين بالإدارات التعليمية بمحافظة القليوبية بالنسبة للمتغير المستقل (الإدارة

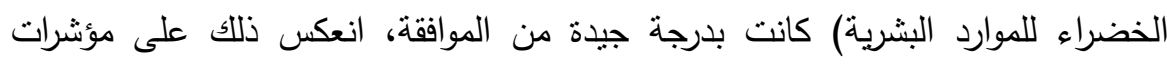

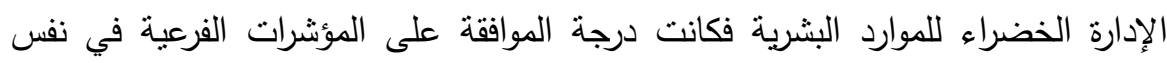
المستوى، وكان مؤشر (التوظيف الأخضر) هو الأعلى منوسط بين المؤشرات يليه

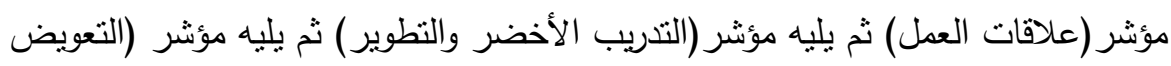

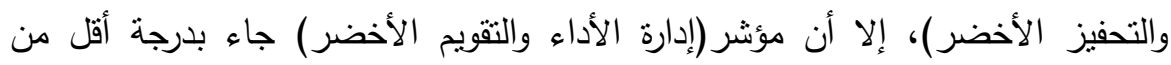

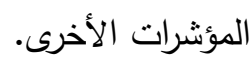

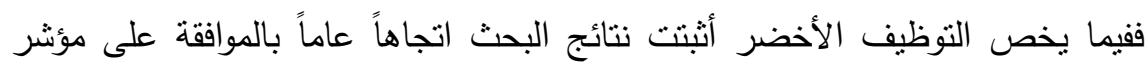
التوظيف الأخضر، حيث اتفت أراء العينة بشدة حول المؤشر (يتم توصيف الوظائف

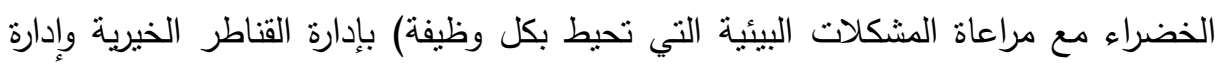

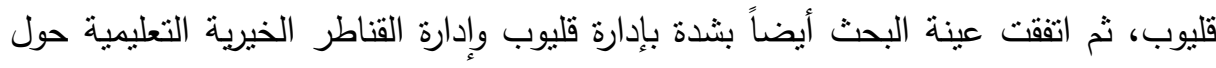
المؤشر (يعتبر الموظف صاحب القيم البيئية السليمة قيمة كبيرة داخل الإدارة)، ثم اتجهت بادرة

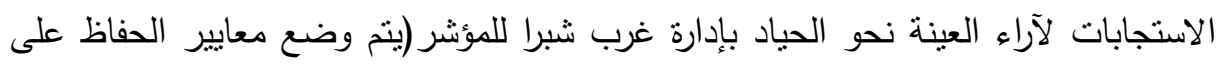

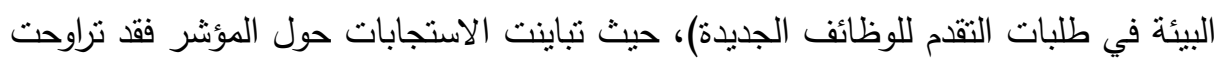

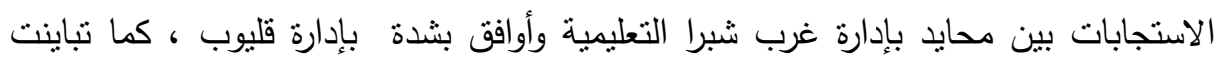

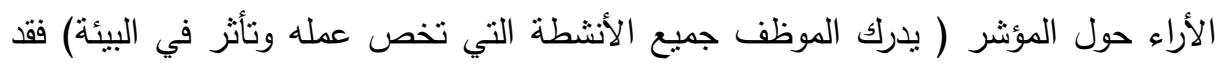
تراوحت الأراء بين محايد بإدارة غرب شبرا التعليمية وإدارة بنها وأوافق بشدة بإدارة قليوب وإدئ وادارة

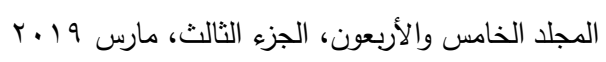


القناطر الخيرية ، ثم جاءت الإجابات بإدارة بنها وإدارة غرب شبرا الخيمة بعدم الموافقة وعدم

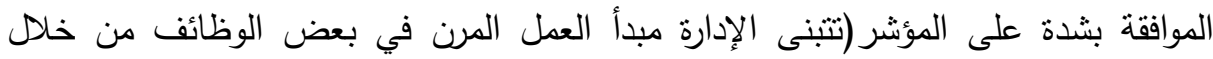
السماح بإنجاز العمل من المنزل). من هنا يرى الباحث أن هناك ضعف في تطبيق بعض مؤشرات التوظيف الأخضر

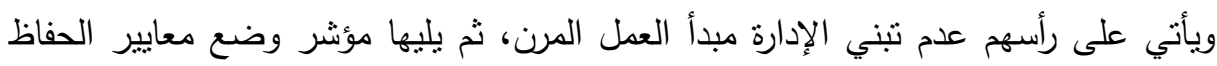
على البيئة في طلبات التقام للوظائف الجديدة، وكذلك مؤشر إدرك الموظف جمئ الديع الأنشطة التي تخص عمله وتأثر في البيئة.

بينما فيما يخص علاقات العمل - فقد تميزت عن بعض مؤشرات الإدارة الخضراء للموارد البشرية بدرجة عالية من الموافقة للعديد من المؤشرات حيث يتبع الموظف الود بهن

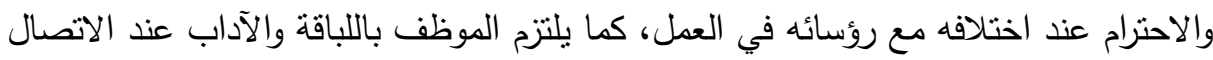

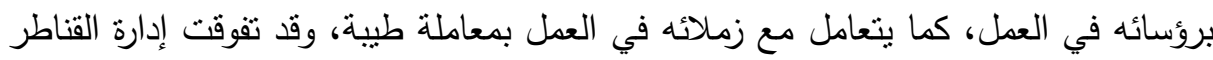

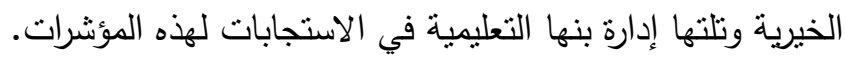

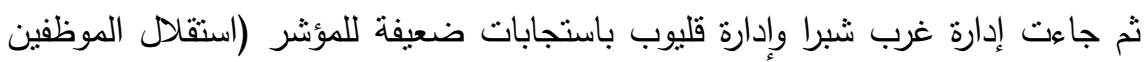
بتجربة الأفكار الخضراء)، ثم المؤشر (تخصيص موظف للمساعدة والإرشاد في المسائل الخضراء صديقة البيئة). ويرى الباحث إن الإدارات التعليمية تتميز بأن هناك علاقات عمل جيدة وأن العلاقة بين الموظفين وبعضهم البعض جيدة، لذا يتطلب من الإدارة الاستعانة بهم في المشاركة في طرح الأفكار الخضراء، كما بمكن تخصيص موظف منهم للمساعدة والإرشاد في المسائل

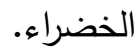

وفيما يخص التدريب الأخضر والتطوير - فكانت الإنتجابات للعينة بدرجة أوافق للمؤشر عامة ووجد الباحث أن هناك تتوع في إجابات المبحوثين حول أغلب العبارات، وكانت

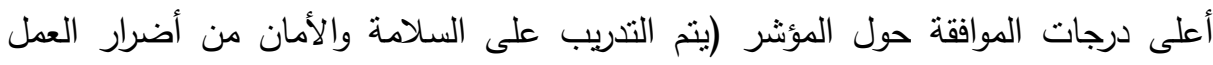

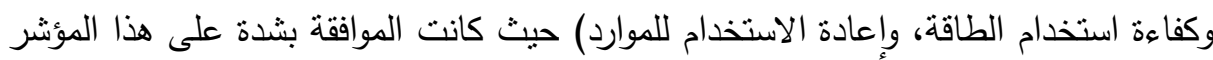
بإدارة قليوب التعليمية، وقد تلاها استجابات العينة بشدة بإدارة القناطر الخيرية للمؤشر (يتم

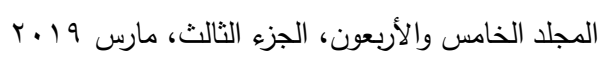


إدخال التدريب الأخضر في الإدارة لجعلها إدارة بيئية)، ثم تلاها أيضاً استجابات العينة بشدة

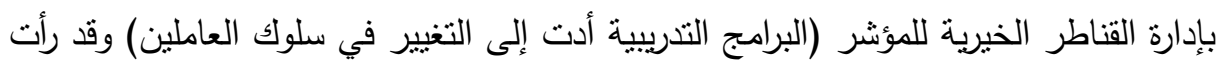

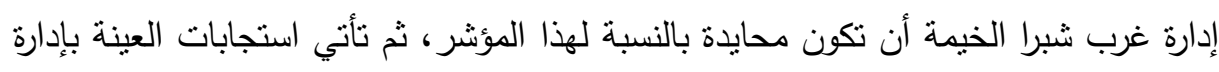

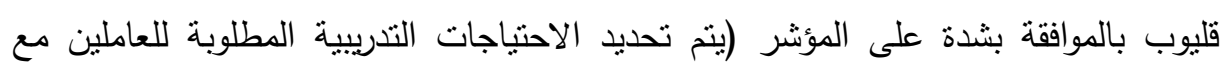
مراعاة الظروف البيئية لكل وظيفة). ثم جاءت أقل الاستجابات للعينة بإدارة غرب شبرا الخيمة للمؤشر (يتم تدريب المديرين

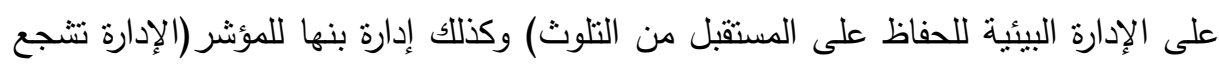

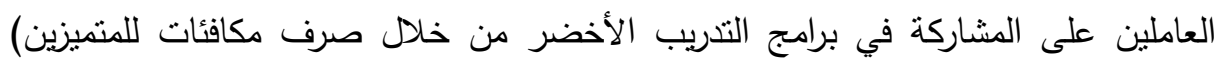

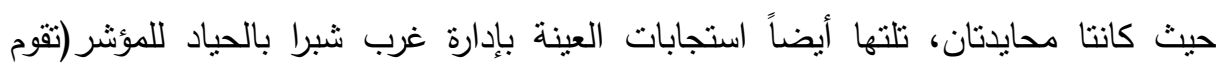
الإدارة بتقييم البرامج التدريبية لنطوير العاملين).

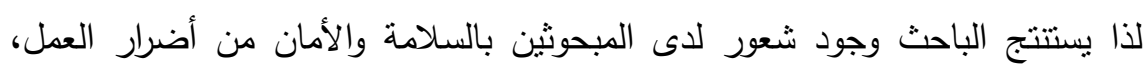

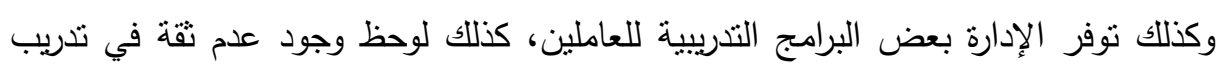

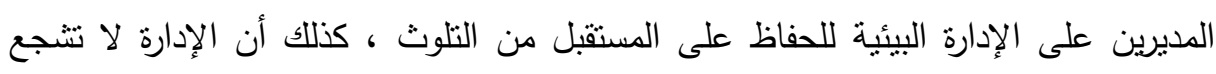

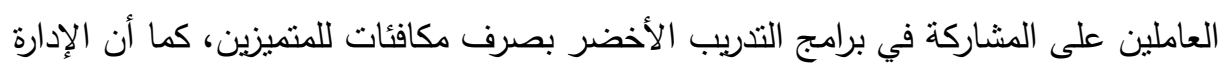

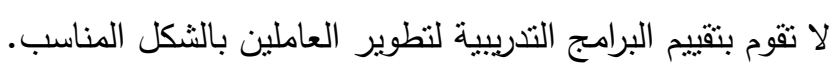

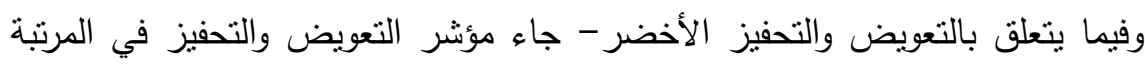

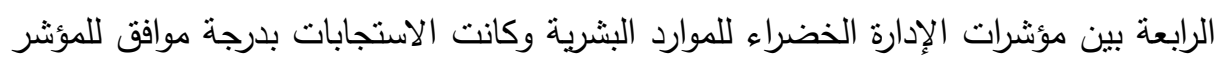

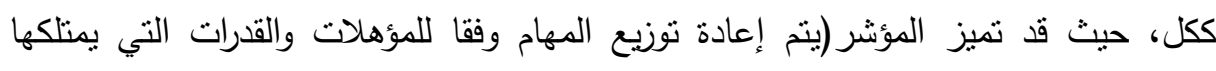
الموظف) بإدارة بنها بدرجة عالية من الموافقة عن باقي المؤشرات، كما يتم تشجيع العاملين الجدد للتكيف مع بيئة العمل في إدارة القناطر الخيرية وكذلك يتم وضع التعزيزات الإيجابية 1ل للعمال بينما تأتي إدارة غرب شبرا باستجابات ضعيفة لمؤشر استخدام الإعفاءات الضريبية

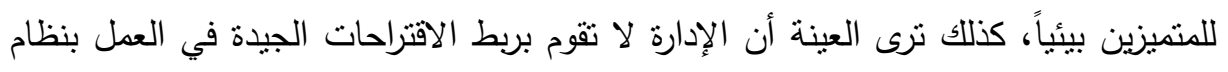
المكافآت، كما إنه لا يتم صرف مكافئات نقدية للعاملين. 
لذا يرى الباحث أنه يمكن استخدام نظام الإعفاءات الضريبية للعاملين المتميزين كأحد أثنكال التحفيز وكذللك مراعاة الاقتراحات الجيدة التي يقدمها العاملين لتحسين العمل بالإدارة، كما يجب وضع نظام للمكافئات النقدية للعاملين. أما فيما يتعلق بإدارة الأداء والتقييم الأخضر - جاء مؤشر إدارة الأداء والتقييم الأخضر

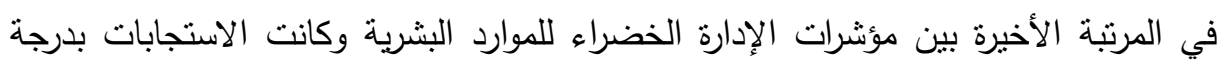

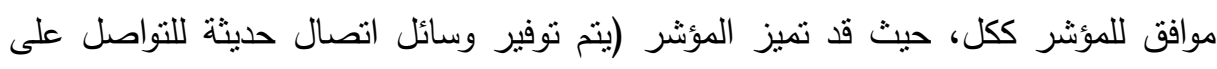
جميع مستويات العاملين) وكانت هذه الاستجابات بإدارة القناطر الخيرية ، ثم استجابة العينة بثدة بإدارة القناطر الخيرية للمؤشر (يتم إقامة حوار موسع مع العاملين على مستوى الإدارة بشأن المشكلات البيئية التي تحيط بعطهم) وكذللك مؤشر (ينت العمل على توفير التكنولوجيا المناسبة لأداء العمل بالسرعة والدقة المطلوبة).

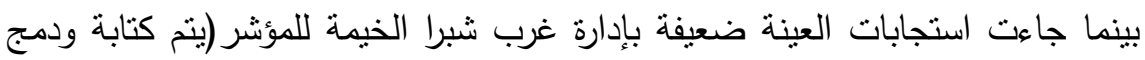

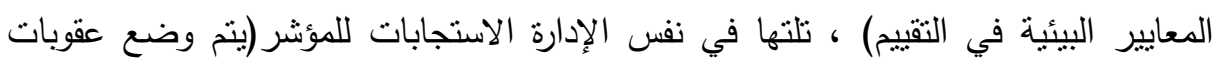
على عدم الالنزام بأهداف الإدارة البيئية). وبشكل عام نجد أن العينة تعتقد في نطبيق الإدارات التعليمية لمتغير (الإدارة الأخضر

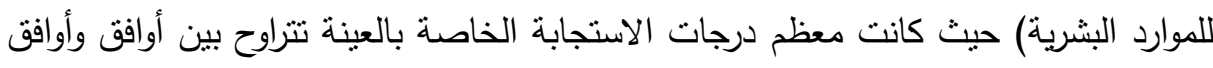

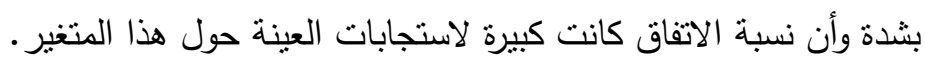

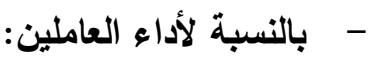
أثنتت نتائج البحث أن عينة البحث نرى أن الإدارات التعليمية تقوم ببعض الإجراءات التي تساعد على تحسين (أداء العاملين) ويتضح ذلك من خلال تطبيق عناصر تحسين (أداء العاملين) كمنغير تابع لتطبيق الإدارة الخضراء للموارد البشرية.

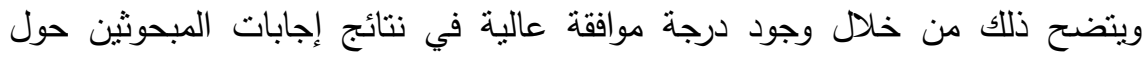
مؤشرات أداء العاملين ككل، وقد نتوعت الاستجابات بين بعض المؤشرات، حيث كانت درجة الموافقة عالية فيما يخص المؤشرات (تقدم التكنولوجيا الحديثة خدمة جيدة للمستفيدين، تتفيذ العمل بالدقة والسرعة نتيجة وجد جو من الألفة والتفاهم بين العاملين، إنجاز المهام الموكلة

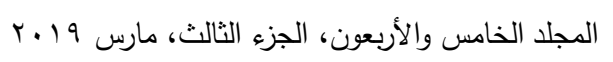


للعاملين يرجع إلى التحفيز المستمر) وكانت هذه الاستجابات للعينة بإدارة القناطر الخيرية

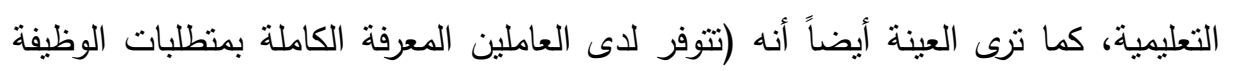
التي يؤدونها).

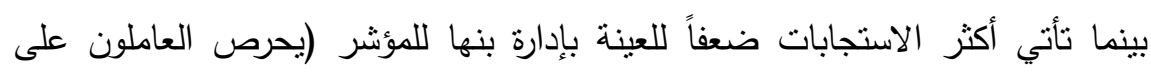

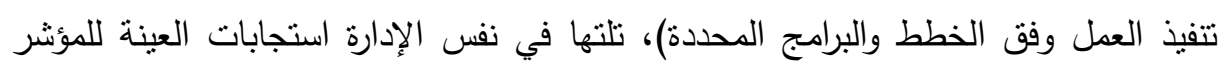
(ساهم العاملون في تحقيق الأهداف الموضوعة للإدارة).

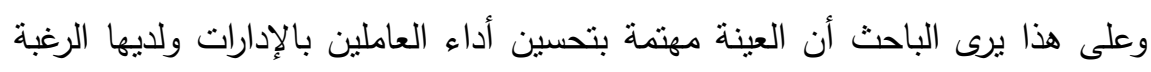
في الوصول إلى ذلك من خلال الاهتمام بممارسات الإدارة الخضراء للموارد البشرية.

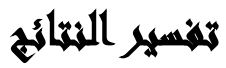

ل قد ثبت وجود ارتباط طردي قوى بين جميع أبعاد (المتغير المستقل) الإدارة الخضراء للموارد البشرية و (أداء العاملين) كمتغير تابع. ل يوجد تأثير ذو دلالة إحصائية لممارسات الإدارة الخضراء للموارد البشرية (التوظيف

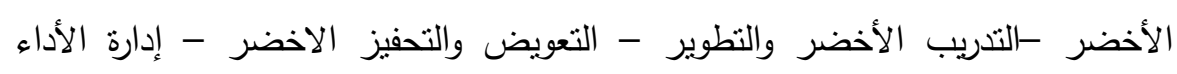
والتقييم الأخضر - علاقات العمل) على أداء العاملين بالإدارات التعليمية " محل البحث.

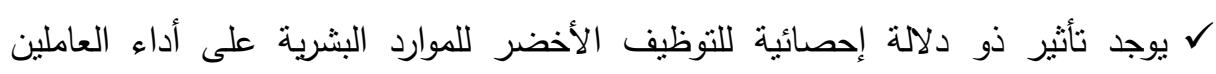

$$
\text { بالإدارات التعليمية. }
$$

ليوجد تأثير ذو دلالة إحصائية للتدريب الأخضر ونطوير الموارد البشرية على أداء العاملين

$$
\text { بالإدارات التعليمية. }
$$

ل يوجد تأثير ذو دلالة إحصائية للتعويض والتحفيز الأخضر للموارد البشرية على أداء

$$
\text { العاملين بالإدارات التعليمية. }
$$

ل يوجد تأثير ذو دلالة إحصائية لإدارة الأداء والتقويم الأخضر على أداء العاملين بالإدارات

$$
\text { التعليمية }
$$

ل يوجد تأثير ذو دلالة إحصائية لعلاقات العمل الخاصة بالموارد البشرية على أداء العاملين

$$
\text { بالإدارات التعليمية ". }
$$


ل وقد توصل البحث إلى وجود نقاط اتفاق واختلاف مع الدراسات السابقة ، حيث اهتمت الدراسات السابقة بالإدارة الخضراء للموارد البشرية (Green HRM) فيما يتعلق بمفهومها

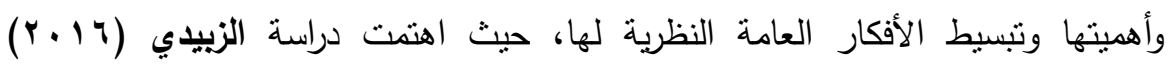

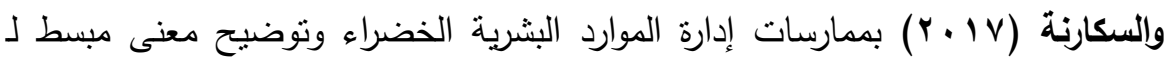
وفاعلية تتفيذها في المنظمات، كما هدفت دراسة Opatha (2014) إلى تبسيط الأفكار العامة النظرية فيما يتعلق بإدارة الموارد البشرية الخضراء وكذللك هدفت دراسة Rimi (2016) إلى وضع نموذج لتحسين ممارسات إدارة الموارد البثرية الخضراء في المنظمات.

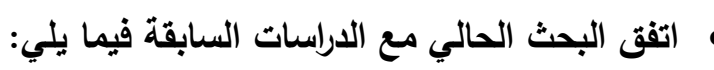
1-الاهتمام بالإدارة الخضراء للموارد البشرية (Green HRM) فيما يتعلق بمفهومها وأهميتها وممارساتها في المنظمات. باترات r-الرجوع إلى الدراسات والبحوث السابقة في التعرف على مفهوم الإدارة الخضراء للموارد البشرية. r-التأكيد أن المورد البشري هو أهم الأصول للمنظمة، وأن إدارة الموارد البشرية تلعب دوراً هاماً في إدارة الموظفين وزيادة اتجاه المنظمة نحو تخضير الألمورد الأعمال والحفاظ على البيئة. ع - اتفقت مع بعض الدراسات السابقة في استخدام المنهج الوصفي التحليلي.

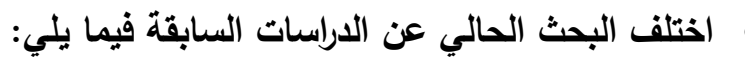

1-الاهتمام بالإدارة الخضراء للموارد البشرية في الإدارات التعليمية أما الدراسات السابقة عنات فاهتمت بالإدارة الخضراء للموارد البشرية في المنظمات الصناعية والبنوك التجارية. r- الدراسة الحالية تقوم على بناء استبانه لجمع البيانات بالإضافة إلى المقابلات الثخصية،

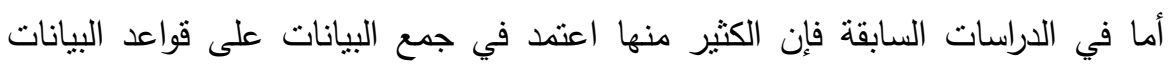
والبحوث السابقة والمواقع الإلكترونية. r- الدراسة الحالية تستخدم المنهج المقارن بالإضافة إلى المنهج الوصفي التحليلي في تقسير البيانات والمعلومات. 
ع-تهتم الدراسة الحالية بتحديد المعوقات التي تحول دون نطبيق الإدارة الخضراء للموارد

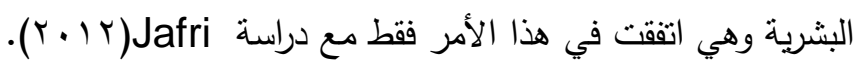
ه- الدراسة الحالية تربط بين الإدارة الخضراء للموارد البشرية بالإدارات التعليمية وتحسين أداء العاملين بها.

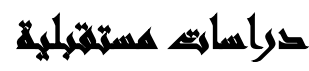

$$
\text { ا-بور الإدارة البيئية في تطوير أداء العاملين. }
$$

r-دور استراتيجيات التدريب الأخضر في رفع كفاءة أداء العاملين. r- أثز دمج تكنولوجيا المعلومات في استراتيجيات التدريب الأخضر على على الأداء التنظيمي.

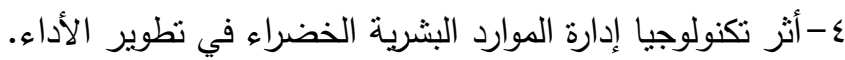

ه- أثر الرضا الوظيفي للعاملين الخضر على تحسين الأداء.

\section{اللتوكيايت}

فى ضوء ما أسفرت عنه نتائج البحث يطيب للباحثين أن يختتموا بحثهم بتقديم

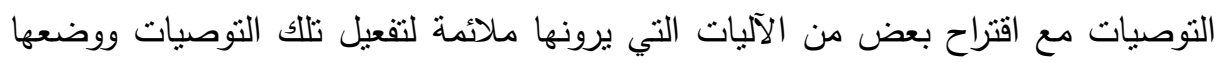
موضع التنفيذ، والجدول التالي رقم (0) يوضح نوصيات البحث وخطوات وجهة التنفيذ. جدول رقم (0): توصيات البحث

\begin{tabular}{|c|c|c|c|c|}
\hline المدى الزمني & جهة التنفيذ & خطوات التطبيق & التوصية & 5 \\
\hline : & $\begin{array}{l}\frac{\overline{2}}{3} \\
\frac{10}{3} \\
3 .\end{array}$ & 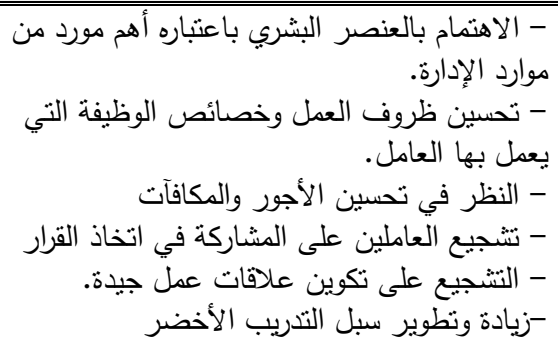 & 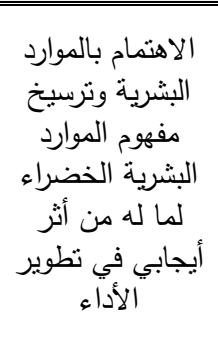 & 1 \\
\hline 预 & $\begin{array}{l}\frac{\bar{\lambda}}{3} \\
\overline{3} \\
\overline{3}\end{array}$ & 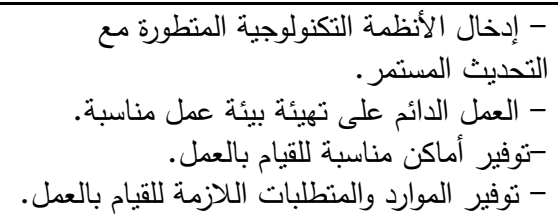 & 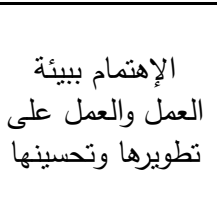 & $r$ \\
\hline
\end{tabular}


تابع جدول رقم (ه): - ت

\begin{tabular}{|c|c|c|c|c|}
\hline الزمنيى & التنفيذ & خطوات التطبيق & التوصية & p \\
\hline 㝵 & 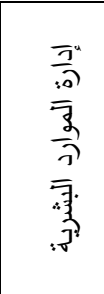 & 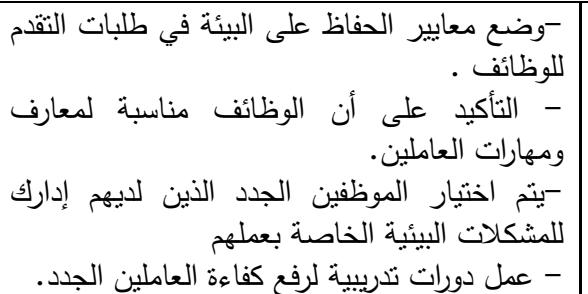 & بجب حل المشكلات المتعلقة & $r$ \\
\hline 等 & $\begin{array}{l}\frac{\overline{7}}{1.0} \\
\overline{3} \\
\overline{3}\end{array}$ & 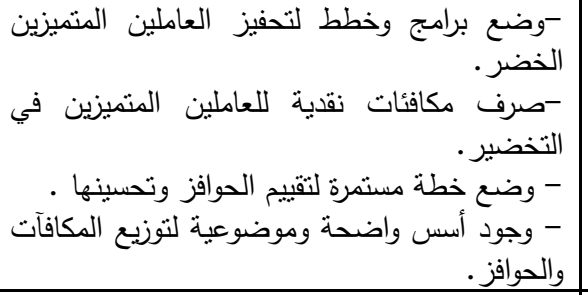 & 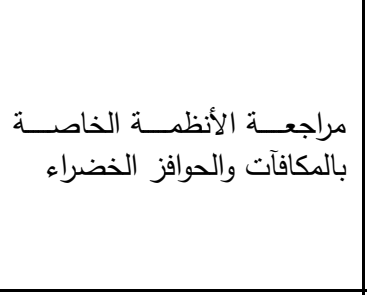 & $\varepsilon$ \\
\hline ד. & $\begin{array}{l}\frac{\overline{2}}{3.0} \\
\overline{3} \\
\overline{3}\end{array}$ & 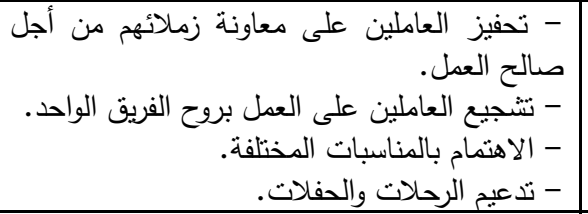 & 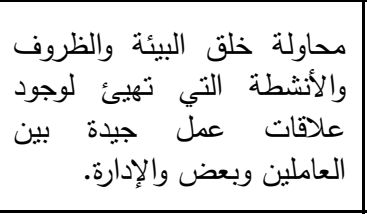 & 0 \\
\hline 学 & 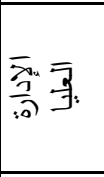 & 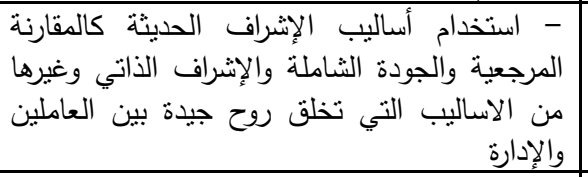 & 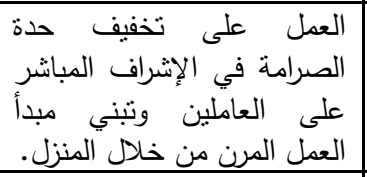 & 9 \\
\hline 勇 & $\begin{array}{l}\overline{7} \\
\overline{3} \\
\overline{3}\end{array}$ & 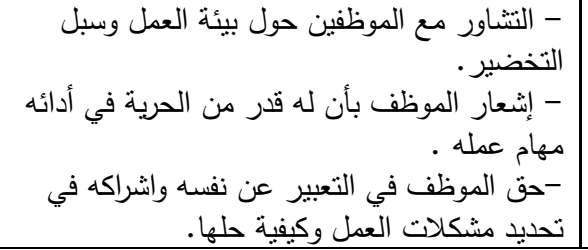 & 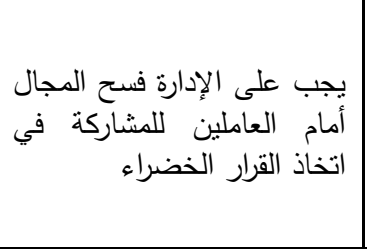 & \\
\hline
\end{tabular}




\section{المراليع}

الأمين، مصطفى محمد إبراهيم، أثر إدارة الموارد البشرية في تطوير أداء العاملين، رسالة

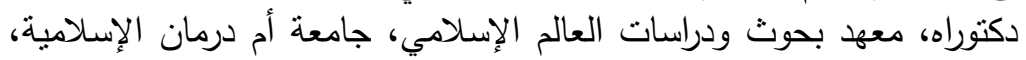

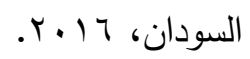

حسن، راوية، إدارة الموارد البشرية: رؤية مستقلية، الدار الجامعية، القاهرة، ؟ . r.

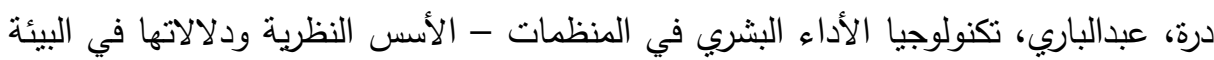

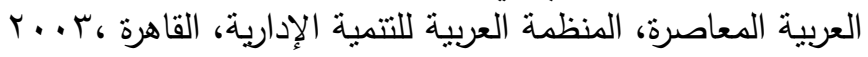

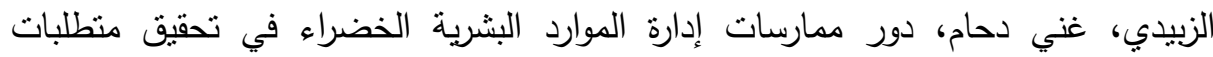

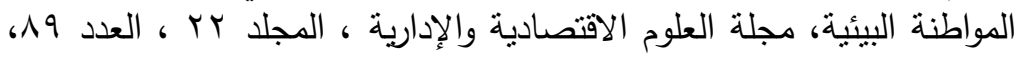

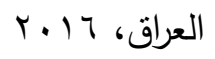

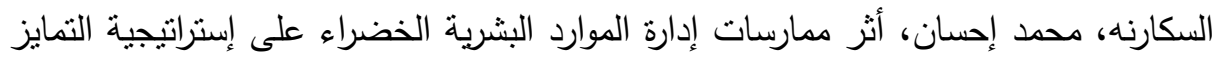

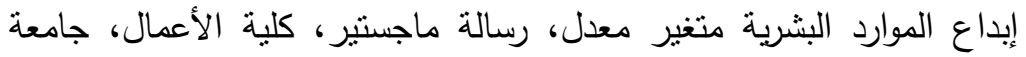

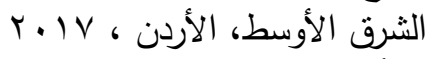

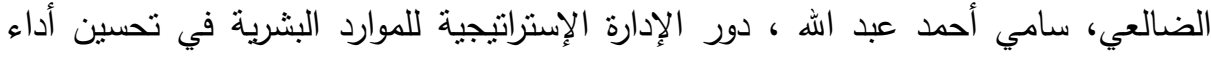

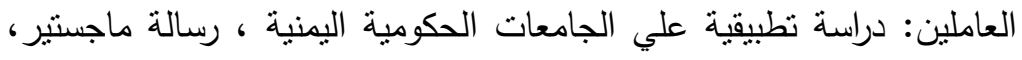

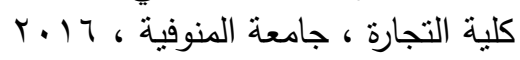

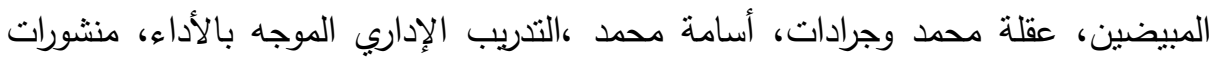
المنظمة العربية للتتمية الإدارية، القاهرة ، 2010

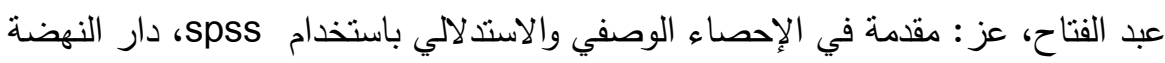

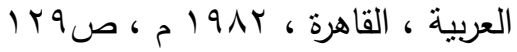

مزهوده، عبد المليك: الأداء بين الكفاءة والفعالية مفهوم وتقييم، مجلة العلوم الإنسانية، جامعة محمد حيضر بسكرة ، 2011 ملأل

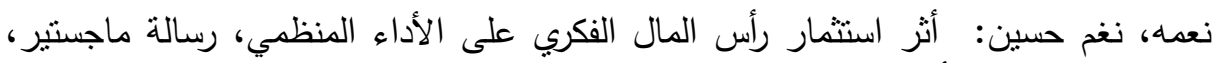
إدارة أعمال، كلية الإدارة والإنتصاد، بغداد، العراق الفكري ، الأن 2002

Ahmad,S.(2015),"Green Human Resource Management: Policies and practices" , Cogent Business \& Management, 2(1), 1030817. 
Amara, N. B., \& Atia, L. (2016)," E-Training And Its Role In Human Resources Development", Global Journal of Human Resource Management, 4(1), 1-12.

Jabbour,C.(2013)," Environmental training in organisations:From a literature review to a framework for future research",Resources,Conservation and Recycling,74:144155

Marhatta.S\&Adhikari.S. (2013)," Green HRM and Sustainability", ASM's International E-Journal of Ongoing Research in management And IT.

Masri,H,A.(2016)," Assessing Green Human Resources Management Practices in West Bank", An-Najah NationalUniversity, Faculty of Graduate Studies.

Müller-Camen, M., Jackson, S. E., Jabbour, C. J., \& Renwick, D. W. S. (2011)," Green human resource management", ZeitschriftfürPersonalforschung, 25(2), 99195.

Opatha, H. H. D. N. P., \& Arulrajah, A. A. (2014),"Green human resource management: simplified general reflections", International Business Research,7(8), 101.

Rimi,N,N.(2016)," Green HRM for Green Services", European Journal of Business and Management, ISSN 2222-1905 (Paper) ISSN 2222-2839 (Online) Vol.8, No ^.

Ruchismita, P; Shitij, R \& Pallavi, S \& Vivek, Y. (2015),"Green HR: Analysis of Sustainable practices Incorporated by IT firms in India",SIMS Journal of Management Research, 1: 12-17.

Shaikh, M. (2010),"Green HRM: A requirement of 21st century", Journal of Research in Commerce and Management, 1, 122-127.

Sharma, R \& Gupta, N. (2016),"Green HRM: An Innovative Approach to Environmental Sustainability", University of Jommu.

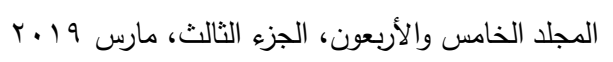


محمد سلامة شديد وآخرون

\title{
THE ROLE OF GREEN HUMAN RESOURCES MANAGEMENT IN IMPROVING THE PERFORMANCE OF THE EMPLOYEES OF THE EDUCATIONAL ADMINISTRATIONS
}

Mohamed S. ElSisi ${ }^{(1)}$; Mamdouh A. Refae $^{(2)}$; Magda M. A. Jibril ${ }^{(2)}$ and Ashraf M. R. Sarg ${ }^{(3)}$

1) Director General of Executive Affairs 2) Faculty of Commerce, Ain Shams University 3) Educational Directorate, Qalyubia

\begin{abstract}
The purpose of this research is to identify the role of green management practices for human resources in improving the performance of employees in educational Administrations in Qalioubia governorate in order to improve the environmental performance of the employees, From the point of view of the research sample, the problem of research is the extent to which the dimensions of green management of human resources affect the performance of employees, the researchers relied on the combination of the descriptive approach and the analytical descriptive approach to describe the problem and analyze the results of the research. A questionnaire list was prepared for the purpose of collecting data according to the search variables, Which represents the green management of human resources (independent variable) and the performance of employees (variable dependent), The randomized sample was $27.47 \%$ of the research population, The researchers came to several results were in, There is a statistically significant effect among all dimensions of green management of human resources, which represents the independent variable and the dependent variable, the performance of workers, The researchers also came up with a set of recommendations, To focus on human resources and to consolidate the concept of green human resources because of its positive impact on the development of performance, attention to the
\end{abstract}

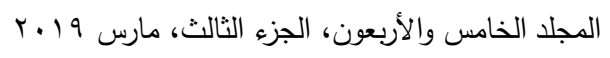


work environment, development and improvement, review of regulations for green rewards and incentives, and adoption of the principle of flexible work through the house. Continuous training in accordance with programs and plans to improve efficiency and improve performance.

Keywords: green management of human resources, green employment, green training and development, green compensation and incentives, green performance and evaluation management, labor relations, employee performance. 